Proceedings of the 10th International Ruminant Reproduction Symposium (IRRS 2018); Foz do Iguaçu, PR, Brazil, September 16th to 20th, 2018.

\title{
Follicular guidance for oocyte developmental competence
}

\author{
Satoshi Sugimura ${ }^{1}$, Dulama Richani ${ }^{2}$, Robert B. Gilchrist ${ }^{2, *}$ \\ ${ }^{1}$ Department of Biological Production, Tokyo University of Agriculture and Technology, Tokyo 183-8509, Japan. \\ ${ }^{2}$ Discipline of Obstetrics \& Gynaecology, Fertility and Research Centre, School of Women's \& Children's Health, University of \\ New South Wales Sydney, 2052, Australia.
}

\begin{abstract}
The advancement of folliculogenesis is coincident with the sequential acquisition of oocyte developmental competence. In practical bovine/porcine ART, cumulus-oocyte complexes (COCs) aspirated from small antral follicles have low developmental competence relative to COCs from medium/large antral follicles, as evidenced by a poor capacity to support embryogenesis up to the blastocyst stage. This is in part because of incomplete differentiation of cumulus cells in small antral follicles, in particular under-developed functionality of EGF signalling. Gonadotrophins and oocyte-secreted paracrine factors cooperate to establish EGF receptor functionality in cumulus cells, which appears to be involved in the acquisition of oocyte developmental competence. Here we review the modification of follicular cumulus cells during antral folliculogenesis involved in oocyte developmental competence.
\end{abstract}

Keywords: cumulus cells, oocyte, oocyte secreted factors.

\section{Introduction}

The developmental competence of an oocyte, referring to its capacity to support fertilization, preimplantation embryo and subsequent full-term development, is inherently linked to environmental cues it receives from the follicular somatic cell compartment (Gilchrist and Thompson, 2007). The follicular soma is regulated principally by gonadotropic cues (FSH and $\mathrm{LH}$ ) during the course of folliculogenesis (Scaramuzzi et al., 2011).

Oocytes acquire increasing developmental competence sequentially with advancing folliculogenesis and as such oocyte and follicle development are inter-dependent processes (Thibault, 1977). Hence, as the obligatory driver of folliculogenesis, FSH is also the central driver of the acquisition of oocyte developmental competence, facilitating a myriad of follicular somatic cell functions that nurture the growth and development of the oocyte. During the terminal phases of folliculogenesis and oogenesis, FSH promotes expression of the LH and epidermal growth factor (EGF) receptors on granulosa cells (Erickson et al., 1979; El-Hayek et al., 2014). FSH also facilitates the bilateral communication between granulosa cells and between the oocyte and granulosa/cumulus cells (CCs) by promoting gap junctional communication (GJC; El-Hayek and Clarke, 2015), likely via cyclic adenosine monophosphate (cAMP)-phosphate kinase A (PKA) pathway activation. Oocyte-CC GJC is responsible for the transfer of small molecules such as cAMP, cyclic guanosine monophosphate (cGMP) and metabolites from the CCs to the oocyte (Sugimura et al., 2014; Li et al., 2016). In addition, vesicles and potentially RNA may traffic to the oocyte from the CC's transzonal projections (Macaulay et al., 2014) which, together with GJC, regulate oocyte meiotic maturation and developmental competence (Sugimura et al., 2014; Li et al., 2016; Russell et al., 2016).

Key propagators of the ovulatory cascade within the follicle are the EGF-like peptides; amphiregulin (AREG), epiregulin, and betacellulin, which are produced by mural granulosa cells in response to $\mathrm{LH}$, and signal via the EGF receptor (EGFR) that is expressed on mural granulosa and CCs (Park et al., 2004; Shimada et al., 2006; Hsieh et al., 2007). EGFR activation, in cooperation with the oocyte-secreted factors (OSFs), stimulates gene expression that enables cumulus expansion and ovulation. Two OSFs that facilitate this and are essential for ovulation and oocyte capture by the infundibulum are bone morphogenetic protein 15 (BMP15) and growth differentiation factor 9 (GDF9), which are structurally similar members of the transforming growth factor $\beta$ family that can also form a heterodimer termed cumulin (Mottershead et al., 2015). Hence, the final steps of oocyte development prior to ovulation are dictated by endocrine cues mediated by the gonadotrophins and by paracrine cues from the oocyte, intersecting in the CCs as the key facilitators of oocyte developmental competence (Russell et al., 2016; Richani and Gilchrist, 2018).

This review will focus on the recent advances in our knowledge of the contribution of endocrine and paracrine cues in the differentiation of follicular granulosa and CCs during antral folliculogenesis, and their contribution to oocyte developmental competence. This knowledge is important for the application of advanced reproductive technologies in domestic animal breeding and in humans. The successful clinical application of the key reproductive technologies of superovulation (combined with artificial insemination or IVF) and oocyte in vitro maturation (IVM) are critically dependent on this knowledge.

\section{EGFR signaling and oocyte developmental competence}

It is now well established that the EGF network is an essential propagator of the ovulatory signal in the 
Graafian follicle to the cumulus-oocyte complex (COC; Park et al., 2004; Conti et al., 2012). The concept that the oocyte sequentially acquires developmental competence to support fetal development throughout antral follicle development has long been clear (Eppig et al., 1992; Lonergan et al., 1994). Hence, oocytes from small antral follicles have a significantly poorer capacity for cumulus expansion and for the support of early embryogenesis, compared with those from large antral follicles. Indeed this concept serves as the basis for the need for superovulation of women undergoing IVF and of cattle undergoing multiple ovulation and embryo transfer (MOET).

Prochazka et al. (2003) hypothesized that porcine COCs from small antral follicles (3-4 $\mathrm{mm}$ ) have an under-developed EGFR. Indeed, there is a growing body of evidence showing that the development of a functional EGF network in follicular granulosa cells is suppressed until the peri-ovular stage as a mechanism of limiting ovulation to the dominant follicle(s), and thus to the developmentally competent oocyte(s); Richani and Gilchrist, 2018). The exact timing of acquisition of functional EGFR signalling in COCs and the associated molecular changes in the oocyte are still unclear, but for experimental purposes such studies commonly divide the antral phase of folliculogenesis in half into small versus large antral follicles. In pigs for example, $<4 \mathrm{~mm}$ (small follicles) vs. $>4 \mathrm{~mm}$ (medium-large follicles) are typically compared (Prochazka et al., 2003; Ritter et al., 2015), whereas in cattle which ovulate larger follicles, a medium-large antral follicle is 6-10 $\mathrm{mm}$ (Lonergan et al., 1994). Using such models, porcine COCs derived from small antral follicles $(<4 \mathrm{~mm})$ are unresponsive to all EGF family ligands and COCs exhibit progressive acquisition of EGF responsiveness with follicle growth (Prochazka et al., 2000, 2003; Diaz et al., 2007; Ritter et al., 2015). The acquisition of EGF signalling capability by $\mathrm{CCs}$ with advancing follicle growth coincides with oocyte acquisition of developmental competence, and the two are likely to be related (Ritter et al., 2015; Sugimura et al., 2015). These latter recent findings suggest that the EGF network may contribute to oocyte quality by providing regulatory cues from the cumulus cells to the oocyte which regulate oocyte integrity (Gilchrist and Richani, 2013; Richani and Gilchrist, 2018). The EGF network also mediates mRNA translation in the transcriptionally silent oocyte during the course of meiotic maturation to the metaphase II stage (Chen et al., 2013). This directly impacts oocyte quality as genetic perturbation of Areg expression in mouse cumulus cells leads to reduced fecundity (Chen et al., 2013).

An understanding of the cellular and molecular mechanisms leading to the development of EGF signalling capabilities with follicle development can provide new approaches for improving the success of oocyte IVM, a reproductive technique that involves the maturation of COCs derived from small antral follicles of unstimulated ovaries (Gilchrist, 2011). Granulosa-type cells (preantral, mural, and cumulus) express EGFR mRNA and protein throughout folliculogenesis, and is activated by a range of EGF family members to promote follicle growth (Roy 1993; Garnett et al., 2002). Several studies have shown that EGFR mRNA expression is lower in small antral follicle CCs than their large antral follicle counterparts (Singh et al., 1995; Prochazka et al., 2003; Caixeta et al., 2009; El-Hayek et al., 2014). However, in a porcine model, we observed (Ritter et al., 2015) CCs from small antral follicles $(<4 \mathrm{~mm})$ exhibit equal expression of EGFR transcripts as those from larger antral follicles $(>4 \mathrm{~mm})$, however EGFR protein production and phosphorylation and subsequent downstream ERK1/2 activity were perturbed. Hence, COCs from small antral follicles are unresponsive to EGF peptides and cannot undergo expansion. There is now good evidence that the EGF signalling network is under-developed in COCs from small antral follicles (Richani and Gilchrist, 2018; Fig. 1).

\section{Establishing cumulus EGFR signaling requires orchestration by endocrine cues and oocyte-secreted factors}

Details of the mechanisms responsible for the maturation of the EGF network in CCs remain unclear, however recent evidence suggests that cooperation between endocrine (FSH) signaling and paracrine signals from the oocyte is essential in this process. FSH plays a major and essential role in follicle development. Follicles of $\mathrm{Fshb}^{-/-}$null mice exhibit perturbations in $\mathrm{CC}$ differentiation and oocyte meiotic maturation, as well as a deficiency in follicle Egfr mRNA expression (El-Hayek et al., 2014). FSH sensitivity is long understood to be a determining factor in follicle selection; recent evidence suggests that this may in part be due to FSH promoting development of a functional EGF network throughout antral follicle growth. Prochazka et al. (2003) demonstrated that in vitro treatment of porcine small antral COCs with FSH promotes EGF responsiveness and subsequent EGFR signaling. EGFR signaling is essential for cumulus expansion, and requires activity of the FSH downstream effector protein kinase A (PKA; Prochazka et al., 2012). Hence, evidence from mice and domestic animal models suggests that endocrine cues are needed for the maturation of the EGF signaling network in CCs, and that the FSH-cAMP-PKA signalling axis mediates this.

Recent evidence has shown that the oocyte itself also significantly contributes to the development of the EGF network throughout the antral phase of folliculogenesis by mediating the effects of FSH. Alone, FSH is insufficient in inducing EGF responsiveness in granulosa and cumulus cells (Fig. 1). Prior to differentiation into cumulus cells, preantral granulosa cells are unable to undergo expansion. Diaz et al. (2006, 2007) showed that this is due to the immaturity of the pre-antral oocyte; murine preantral granulosa acquire the capacity to undergo EGF-induced expansion if cultured with oocytes from large antral follicles as well as treated with FSH, suggesting that the oocyte modulates its secretome to regulate the follicle's response to external endocrine cues. In addition, Sugimura et al. 2015) recently showed that small antral porcine COCs can be induced to respond to AREG following exposure 
to the FSH effector cAMP. However, this required the exogenous addition of GDF9 or BMP15, since cAMP alone had little effect on AREG-induced meiotic maturation, cumulus expansion, ERK1/2 phosphorylation, or blastocyst development in small antral oocytes in the absence of GDF9 and BMP15 (Sugimura et al., 2015). This is consistent with the findings that GDF9 and BMP15 facilitate CC EGFR expression via SMAD2/3 (Su et al., 2010), and that for full GDF9 signalling to occur, cooperation between the EGFR-ERK1/2 and SMAD2/3 pathways in granulosa and cumulus cells is required (Sasseville et al., 2010). EGF responsiveness can be induced in CCs from small antral follicles $(<4 \mathrm{~mm})$ by co-culture with oocytes from larger antral follicles ( $>4 \mathrm{~mm})$ (Ritter et al., 2015). In contrast, EGF responsiveness in CCs from small antral follicles cannot be induced by co-culturing with low competence oocytes of small antral follicles, demonstrating that native factors secreted from developmentally competent oocytes mediate this process, and that the oocyte alters its secretome throughout folliculogenesis to regulate $\mathrm{CC}$ acquisition of EGFR signaling. This suggests that EGF responsiveness is a milestone in the growth and development of the COC throughout folliculogenesis (Ritter et al., 2015). This mechanism is likely in place to perturb meiotic resumption and ovulation of oocytes that have not completed folliculogenesis which are growing in the presence of continual surges of endocrine LH and FSH during menstrual cycles. Hence, in the same way that FSH promotion of $\mathrm{LH}$ receptor signalling marks the development of mural granulosa cells, dual oocyte- and endocrine FSH-induction of EGF responsiveness in $\mathrm{CCs}$ represents a developmental milestone in folliculogenesis (Fig. 1; Ritter et al., 2015; Richani and Gilchrist, 2018).

\section{Small Antral Follicle (EGF-p unresponsive)}
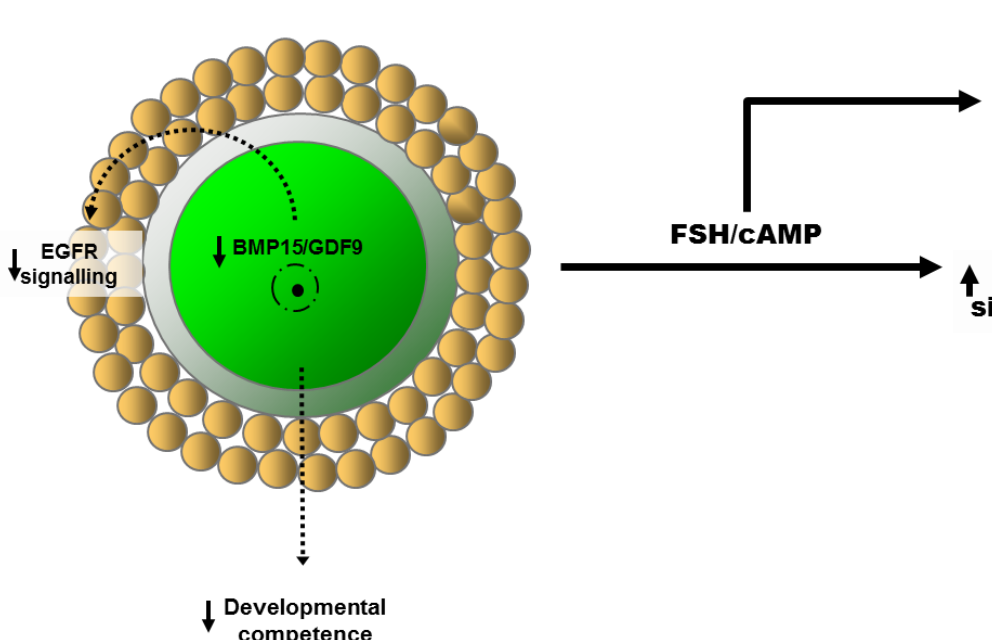

\section{Large Antral Follicle (EGF-p responsive)}

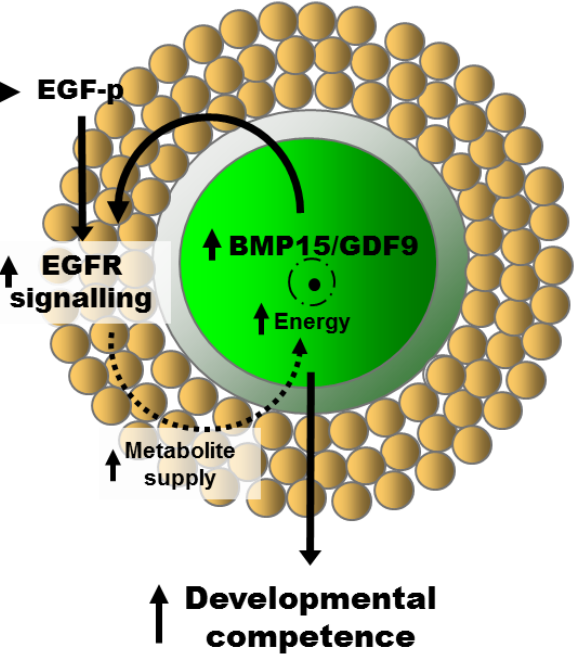

Figure 1. Hypothetical mechanism of cooperation between endocrine FSH priming and oocyte paracrine signals to promote EGFR signaling in cumulus cells. The acquisition of EGFR signaling capability by cumulus cells is a developmental hallmark for the COC. Cumulus-oocyte complexes derived from small antral follicles, which have low developmental competence, exhibit under-developed EGFR signaling as they are unresponsive to EGF-peptides (EGF-p). As folliculogenesis progresses, EGFR functionality is induced in COCs by the concerted actions of FSH/cAMP and oocyte-secreted factors (of which BMP15 and GDF9/cumulin have been identified), and is associated with increased oocyte developmental competence. Improved oocyte developmental competence may be facilitated by EGF-peptide stimulation of cumulus cell glycolysis and provision of metabolites (e.g. NAD(P)H) to the oocyte facilitating oocyte mitochondrial activity and energy production needed for development. Figure from Richani and Gilchrist (2018) adapted from Sugimura et al. (2015) with permission.

\section{Modification of cumulus cells by FSH-priming}

As mentioned above, promotion of EGFR signalling in CCs might be a key component in the acquisition of oocyte developmental competence (Ritter et al., 2015; Richani and Gilchrist, 2018). However, this is not the full story since the CCs of mouse COCs derived from small antral follicles which have received no gonadotropin priming are able to undergo a degree of expansion in vitro (Vanderhyden et al., 1990; Wigglesworth et al., 2015). CCs from small antral follicles exhibit a more immature capacity for metabolism, inter-cell communication and cell differentiation at the transcriptome level (Wigglesworth et al., 2015), suggesting that the EGFR network is likely one of several signaling pathways which develop with follicle growth to participate in the acquisition of oocyte developmental competence.

In vivo priming of follicles prior to final oocyte maturation enhances oocyte developmental competence (Hendriksen et al., 2000). This priming can be driven by exogenous FSH administration; the oocytes derived from 
cows subjected to FSH treatment prior to oocyte collection are more developmentally advanced than those from unstimulated cows (Sirard et al., 1999; Sugimura et al., 2012), likely due in large part to the drastically altered transcriptome it induces in CCs (Fig. 2; Sugimura et al., 2017). Our recent RNA-seq analysis showed substantial alteration to $\mathrm{CC}$ gene transcription following in vivo FSH-priming, with the majority of altered transcriptomic genes being downregulated (Sugimura et al., 2017). Surprisingly, the matrix-formation genes HAS2, TNFIP6, and PTX3, which are typically up-regulated in CCs during oocyte maturation and are associated with oocyte developmental capacity (Gebhardt et al., 2011; Wathlet et al., 2011), were downregulated, however this may be attributed to the timing of cell collection, whereby CCs were collected from immature unexpanded COCs (Sugimura et al., 2017).

FSH-priming also enhances $\mathrm{CC}$ transcripts associated with interferon signaling and interferon regulatory factor (IRF) activation, including interferon-stimulated genes (Sugimura et al., 2017). IRF7, a regulator of the viral IFN $\alpha / \beta$ immune response (Honda et al., 2005), ranked first in the list of activated upstream regulators in CCs from FSH-primed cows (Sugimura et al., 2017). TGFB1 regulates IRF7 expression whereby prolonged exposure to TGFB1 promotes downregulation of IRF7 (Cohen et al., 2014). In granulosa cells, increased TGFB1 is a hallmark of the activated inflammatory process, which may stimulate follicular atresia (Hatzirodos et al., 2014a). Pathway analysis predicted TGFB1 as an inhibited upstream regulator and the expression of TGFB1 and the receptor TGFR2 were lower in CCs from animals primed with FSH (Sugimura et al., 2017). In addition, CC expression of transcripts associated with follicle atresia, including TSP1 downregulation and TGFB and TP53 upregulation, (Thomas et al., 2008), is suppressed by FSH-priming. FSH-priming also upregulated cumulus expression of CYP19A1, an indicator of healthy large follicles (Irving-Rodgers et al., 2009; Hatzirodos et al., 2014b). In the natural oestrus cycle of mono-ovulatory animals, a dominant follicle is ultimately selected for ovulation, whilst other growing follicles undergo atresia induced by granulosa cell signalling; as a result of the decrease in survival factors, predominantly FSH (Scaramuzzi et al., 2011). Hence, most COCs collected from antral follicles from a natural oestrus cycle ovary come from follicles at varying stages of atresia. Artificial control of follicular development through the administration of exogenous FSH rescues many antral follicles from atresia via promotion of survival by promoting anti-inflammatory mechanisms such as IRF7 (Sugimura et al., 2017). Whilst LH-induced ovulation induces an inflammatory cascade across the follicle, prior to the LH-surge, FSH is responsible for maintaining an anti-inflammatory state to maintain CC integrity. FSH causes suppression of STAT3 signaling (Ilha et al., 2015), and genetic perturbation of STAT3 expression has been shown to increase expression of IFN $\alpha / \beta$ response genes, including OAS and IRF7 (Wang et al., 2011). Hence, the net effect on COCs of FSH-priming of animals is decreased inflammatory signals and atresia, contributing to increased oocyte developmental competence (Fig. 2).

\section{Low competence (FSH-unprimed)}

\section{High competence (FSH-priming)}

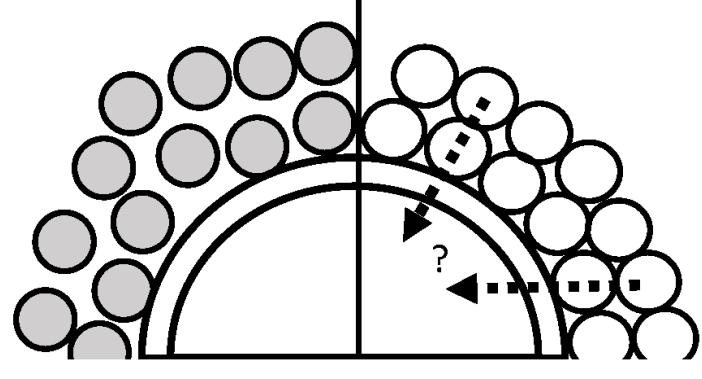

$$
\begin{aligned}
& \rightarrow \text { Nutritional/molecule transfer } \\
& \text { O Atresia } \\
& \text { O Healthy (anti-inflammation) }
\end{aligned}
$$

Figure 2. Hypothetical model of the effect of FSH-priming on bovine cumulus cells based on RNA-seq expression signature. Cumulus cells in a low competence model without FSH-priming exhibit a transcriptomic signature suggestive of decreased inter-cell communication, increased atresia, and driving a spontaneous ovulation-like cascade Conversely, cumulus cells in a high competence model following FSH-priming are in a state of increased inter-cell communication which promotes the transport of molecules from cumulus cells to oocytes, and exhibit increased anti-inflammatory signals at the time of final oocyte maturation. Figure adapted from Sugimura et al. (2017). 


\section{Conclusion}

An important function of follicular somatic cells in follicles approaching ovulation is to prepare the oocyte for final maturation, in part by promotion of cumulus EGFR signaling, as well as prevention of inflammation and promotion of cell-to-cell communication. The latter facilitates the efficient transfer of molecules from the somatic compartment of the follicle to the oocyte. These processes are likely to constitute important components of oocyte developmental competence in humans and ruminants.

\section{References}

Caixeta ES, Ripamonte P, Franco MM, Junior JB, Dode MA. 2009. Effect of follicle size on mRNA expression in cumulus cells and oocytes of Bos indicus: an approach to identify marker genes for developmental competence. Reprod Fertil Dev, 21:655-664.

Chen J, Torcia S, Xie F, Lin CJ, Cakmak H, Franciosi F, Horner K, Onodera C, Song JS, Cedars MI, Ramalho-Santos M, Conti M. 2013. Somatic cells regulate maternal mRNA translation and developmental competence of mouse oocytes. Nat Cell Biol, 15:1415-1423.

Cohen M, Matcovitch O, David E, Barnett-Itzhaki Z, Keren-Shaul H, Blecher-Gonen R, Jaitin DA, Sica A, Amit I, Schwartz M. 2014. Chronic exposure to TGFbeta1 regulates myeloid cell inflammatory response in an IRF7-dependent manner. EMBO J, 33:2906-2921.

Conti M, Hsieh M, Zamah AM, Oh JS. 2012. Novel signaling mechanisms in the ovary during oocyte maturation and ovulation. Mol Cell Endocrinol, 356:65-73. Diaz FJ, O'Brien MJ, Wigglesworth K, Eppig JJ. 2006. The preantral granulosa cell to cumulus cell transition in the mouse ovary: development of competence to undergo expansion. Dev Biol, 299:91-104.

Diaz FJ, Wigglesworth K, Eppig JJ. 2007. Oocytes are required for the preantral granulosa cell to cumulus cell transition in mice. Dev Biol, 305:300-311.

El-Hayek S, Demeestere I, Clarke HJ. 2014. Follicle-stimulating hormone regulates expression and activity of epidermal growth factor receptor in the murine ovarian follicle. Proc Natl Acad Sci USA, 111:16778-16783.

El-Hayek S, Clarke HJ. 2015. Follicle-stimulating hormone increases gap junctional communication between somatic and germ-line follicular compartments during murine oogenesis. Biol Reprod, 93:47. doi: 10.1095/biolreprod.115.129569.

Eppig JJ, Schroeder AC, O'Brien MJ. 1992. Developmental capacity of mouse oocytes matured in vitro: effects of gonadotrophic stimulation, follicular origin and oocyte size. J Reprod Fertil, 95:119-127.

Erickson GF, Wang C, Hsueh AJ. 1979. FSH induction of functional LH receptors in granulosa cells cultured in a chemically defined medium. Nature, 279:336-338.

Garnett K, Wang J, Roy SK. 2002. Spatiotemporal expression of epidermal growth factor receptor messenger RNA and protein in the hamster ovary: follicle stage-specific differential modulation by follicle-stimulating hormone, luteinizing hormone, estradiol, and progesterone. Biol Reprod, 67:1593-1604. Gebhardt KM, Feil DK, Dunning KR, Lane M, Russell DL. 2011. Human cumulus cell gene expression as a biomarker of pregnancy outcome after single embryo transfer. Fertil Steril, 96:47-52, e42.

Gilchrist RB, Thompson JG. 2007. Oocyte maturation: emerging concepts and technologies to improve developmental potential in vitro. Theriogenology, 67:6-15. Gilchrist RB. 2011. Recent insights into oocyte-follicle cell interactions provide opportunities for the development of new approaches to in vitro maturation. Reprod Fertil Dev, 23:23-31.

Gilchrist RB, Richani D. 2013. Somatic guidance for the oocyte. Dev Cell, 27:603-605.

Hatzirodos N, Hummitzsch K, Irving-Rodgers HF, Harland ML, Morris SE, Rodgers RJ. 2014a. Transcriptome profiling of granulosa cells from bovine ovarian follicles during atresia. BMC Genomics, 15:40. doi: 10.1186/1471-2164-15-40.

Hatzirodos N, Irving-Rodgers HF, Hummitzsch K, Harland ML, Morris SE, Rodgers RJ. 2014b. Transcriptome profiling of granulosa cells of bovine ovarian follicles during growth from small to large antral sizes. BMC Genomics, 15:24. doi: 10.1186/1471-2164-15-24.

Hendriksen PJ, Vos PL, Steenweg WN, Bevers MM, Dieleman SJ. 2000. Bovine follicular development and its effect on the in vitro competence of oocytes. Theriogenology, 53:11-20.

Honda K, Yanai H, Negishi H, Asagiri M, Sato M, Mizutani T, Shimada N, Ohba Y, Takaoka A, Yoshida N, Taniguchi T. 2005. IRF-7 is the master regulator of type-I interferon-dependent immune responses. Nature, 434:772-777.

Hsieh M, Lee D, Panigone S, Horner K, Chen R, Theologis A, Lee DC, Threadgill DW, Conti M. 2007. Luteinizing hormone-dependent activation of the epidermal growth factor network is essential for ovulation. Mol Cell Biol, 27:1914-1924.

Ilha GF, Rovani MT, Gasperin BG, Antoniazzi AQ, Goncalves PB, Bordignon V, Duggavathi R. 2015. Lack of FSH support enhances LIF-STAT3 signaling in granulosa cells of atretic follicles in cattle. Reproduction, 150:395-403.

Irving-Rodgers HF, Harland ML, Sullivan TR, Rodgers RJ. 2009. Studies of granulosa cell maturation in dominant and subordinate bovine follicles: novel extracellular matrix focimatrix is co-ordinately regulated with cholesterol side-chain cleavage CYP11A1. Reproduction, 137:825-834.

Li HJ, Sutton-McDowall ML, Wang X, Sugimura S, Thompson JG, Gilchrist RB. 2016. Extending prematuration with cAMP modulators enhances the cumulus contribution to oocyte antioxidant defence and oocyte quality via gap junctions. Hum Reprod, 31:810-821.

Lonergan P, Monaghan P, Rizos D, Boland MP, Gordon I. 1994. Effect of follicle size on bovine oocyte quality and developmental competence following maturation, fertilization, and culture in vitro. $\mathrm{Mol}$ Reprod Dev, 37:48-53. 
Macaulay AD, Gilbert I, Caballero J, Barreto R, Fournier E, Tossou P, Sirard MA, Clarke HJ, Khandjian EW, Richard FJ, Hyttel P, Robert C. 2014. The Gametic synapse: RNA transfer to the bovine oocyte. Biol Reprod, 91:90. doi: 10.1095/biolreprod.114.119867.

Mottershead DG, Sugimura S, Al-Musawi SL, Li JJ, Richani D, White MA, Martin GA, Trotta AP, Ritter LJ, Shi J, Mueller TD, Harrison CA, Gilchrist RB 2015. Cumulin, an oocyte-secreted heterodimer of the transforming growth factor-beta family, is a potent activator of granulosa cells and improves oocyte quality. J Biol Chem, 290:24007-24020.

Park JY, Su YQ, Ariga M, Law E, Jin SL, Conti M. 2004. EGF-like growth factors as mediators of LH action in the ovulatory follicle. Science, 303:682-684.

Prochazka $R$, Srsen V, Nagyova E, Miyano $T$, Flechon JE. 2000. Developmental regulation of effect of epidermal growth factor on porcine oocyte-cumulus cell complexes: nuclear maturation, expansion, and F-actin remodeling. Mol Reprod Dev, 56:63-73.

Prochazka R, Kalab P, Nagyova E. 2003. Epidermal growth factor-receptor tyrosine kinase activity regulates expansion of porcine oocyte-cumulus cell complexes in vitro. Biol Reprod, 68:797-803

Prochazka R, Blaha M, Nemcova L. 2012. Signaling pathways regulating FSH- and amphiregulin-induced meiotic resumption and cumulus cell expansion in the pig. Reproduction, 144:535-546.

Richani D, Gilchrist RB. 2018. The epidermal growth factor network: role in oocyte growth, maturation and developmental competence. Hum Reprod Update, 24:1-14. Ritter LJ, Sugimura S, Gilchrist RB. 2015. Oocyte induction of EGF responsiveness in somatic cells is associated with the acquisition of porcine oocyte developmental competence. Endocrinology, 156:2299-2312.

Roy SK. 1993. Epidermal growth factor and transforming growth factor-beta modulation of follicle-stimulating hormone-induced deoxyribonucleic acid synthesis in hamster preantral and early antral follicles. Biol Reprod, 48:552-557.

Russell DL, Gilchrist RB, Brown HM, Thompson JG 2016. Bidirectional communication between cumulus cells and the oocyte: old hands and new players? Theriogenology, 86:62-68.

Sasseville M, Ritter LJ, Nguyen TM, Liu F, Mottershead DG, Russell DL, Gilchrist RB. 2010. Growth differentiation factor 9 signaling requires ERK1/2 activity in mouse granulosa and cumulus cells. J Cell Sci, 123:3166-3176.

Scaramuzzi RJ, Baird DT, Campbell BK, Driancourt MA, Dupont J, Fortune JE, Gilchrist RB, Martin GB, McNatty KP, McNeilly AS, Monget P, Monniaux D, Viñoles C, Webb R. 2011. Regulation of folliculogenesis and the determination of ovulation rate in ruminants. Reprod Fertil Dev, 23:444-467.

Shimada M, Hernandez-Gonzalez I, GonzalezRobayna I, Richards JS. 2006. Paracrine and autocrine regulation of epidermal growth factor-like factors in cumulus oocyte complexes and granulosa cells: key roles for prostaglandin synthase 2 and progesterone receptor. Mol Endocrinol, 20:1352-1365.
Singh B, Rutledge JM, Armstrong DT. 1995. Epidermal growth factor and its receptor gene expression and peptide localization in porcine ovarian follicles. Mol Reprod Dev, 40:391-399.

Sirard MA, Picard L, Dery M, Coenen K, Blondin P. 1999. The time interval between FSH administration and ovarian aspiration influences the development of cattle oocytes. Theriogenology, 51:699-708.

Su YQ, Sugiura K, Li Q, Wigglesworth K, Matzuk MM, Eppig JJ. 2010. Mouse oocytes enable LH-induced maturation of the cumulus-oocyte complex via promoting EGF receptor-dependent signaling. Mol Endocrinol, 24:1230-1239.

Sugimura S, Kobayashi S, Hashiyada Y, Ohtake M, Kaneda M, Yamanouchi T, Matsuda H, Aikawa Y, Watanabe S, Nagai T, Kobayashi E, Konishi K, Imai K. 2012. Follicular growth-stimulated cows provide favorable oocytes for producing cloned embryos. Cell Reprogram, 14:29-37.

Sugimura S, Ritter LJ, Sutton-McDowall ML, Mottershead DG, Thompson JG, Gilchrist RB. 2014. Amphiregulin co-operates with bone morphogenetic protein 15 to increase bovine oocyte developmental competence: effects on gap junction-mediated metabolite supply. Mol Hum Reprod, 20:499-513.

Sugimura S, Ritter LJ, Rose RD, Thompson JG, Smitz J, Mottershead DG, Gilchrist RB. 2015. Promotion of EGF receptor signaling improves the quality of low developmental competence oocytes. Dev Biol, 403:139-149.

Sugimura S, Kobayashi N, Okae H, Yamanouchi T, Matsuda H, Kojima T, Yajima A, Hashiyada Y, Kaneda M, Sato K, Imai K, Tanemura K, Arima T, Gilchrist RB. 2017. Transcriptomic signature of the follicular somatic compartment surrounding an oocyte with high developmental competence. Sci Rep, 7:6815. doi: 10.1038/s41598-017-07039-5.

Thibault C. 1977. Hammond memorial lecture. Are follicular maturation and oocyte maturation independent proccesses? J Reprod Fertil, 51:1-15.

Thomas FH, Wilson H, Silvestri A, Fraser HM. 2008. Thrombospondin-1 expression is increased during follicular atresia in the primate ovary. Endocrinology, 149:185-192.

Vanderhyden BC, Caron PJ, Buccione R, Eppig JJ. 1990. Developmental pattern of the secretion of cumulus expansion-enabling factor by mouse oocytes and the role of oocytes in promoting granulosa cell differentiation. Dev Biol, 140:307-317.

Wang WB, Levy DE, Lee CK. 2011. STAT3 negatively regulates type I IFN-mediated antiviral response. J Immunol, 187:2578-2585

Wathlet S, Adriaenssens T, Segers I, Verheyen G, Van de Velde H, Coucke W, Ron El R, Devroey P, Smitz J. 2011. Cumulus cell gene expression predicts better cleavage-stage embryo or blastocyst development and pregnancy for ICSI patients. Hum Reprod, 26:1035-1051.

Wigglesworth K, Lee KB, Emori C, Sugiura K, Eppig JJ. 2015. Transcriptomic diversification of developing cumulus and mural granulosa cells in mouse ovarian follicles. Biol Reprod, 92:23. doi: 10.1095/biolreprod.114.121756. 